\title{
VALUE STREAM MAPPING IMPLEMENTATION TACTIC AS A LEAN TOOL
}

\author{
Shyam Sunder Suthar ${ }^{1}$
}

Abstract-An efficient and qualitative product can be achieved by implementing LM. LM is referred as approaches initially developed by Toyota that focuses on elimination of waste in all forms. Value stream mapping is a visual representation of all the specific activities, including the flow of material and information, which occurs along the value stream selected for a product or family. This paper illustrates the VSM implementation tactic as a lean tool in manufacturing and assembly industries. The purpose of this paper is to highlight the effective tactic of the VSM implementation for process parameter improvements by different authors.

Keywords - Lean manufacturing, value stream mapping, WIP

\section{INTRODUCTION}

The main goal of manufacturing organization is to fulfill customer demand by providing an exact product with high quality, required quantity and at a minimum price in the shortest time possible. In order to meet the organizational goal and compete with global market, there is a need to improve productivity and quality of product. Lean manufacturing (LM) considered as waste reducing mechanism and after implementation of LM manufacturing organization became an outstanding organization. LM considered as one potential approach for improving organizational productivity [1]. LM based Companies are achieving the remarkable improvement in efficiency. Lean manufacturing believes the simple fact that customer will pay for the value of services they receive, but will not pay for mistakes [2].Value is addition that attracts end customer. The whole process of the value addition should be observed and optimized from the end customer's point of view[3].

\section{VALUE STREAM MAPPING 2.1 VALUE STREAM MAPPING}

Value stream mapping is a visual representation of all the specific activities, including the flow of material and information, which occurs along the value stream selected for a product or family [4]. Value Stream Mapping is a manual method for mapping. It represents all activities of product from raw material to finished product in the hand of customer. Software used to draw the value stream map for current and future state VSM are listed below
a) SimCAD
f) Eves
b) Breeze Tree
g) Lucid chart
c) Edraw
h) Microsoft Visio
d) Smart Draw
e) Leanpilot

\subsection{VALUE STREAM MAP ICONS}

Various icons used to draw value stream map. Some of them are shown in Fig.2.1

\footnotetext{
${ }^{1}$ ECB Polytechnic College, Bikaner, Rajasthan, India
} 


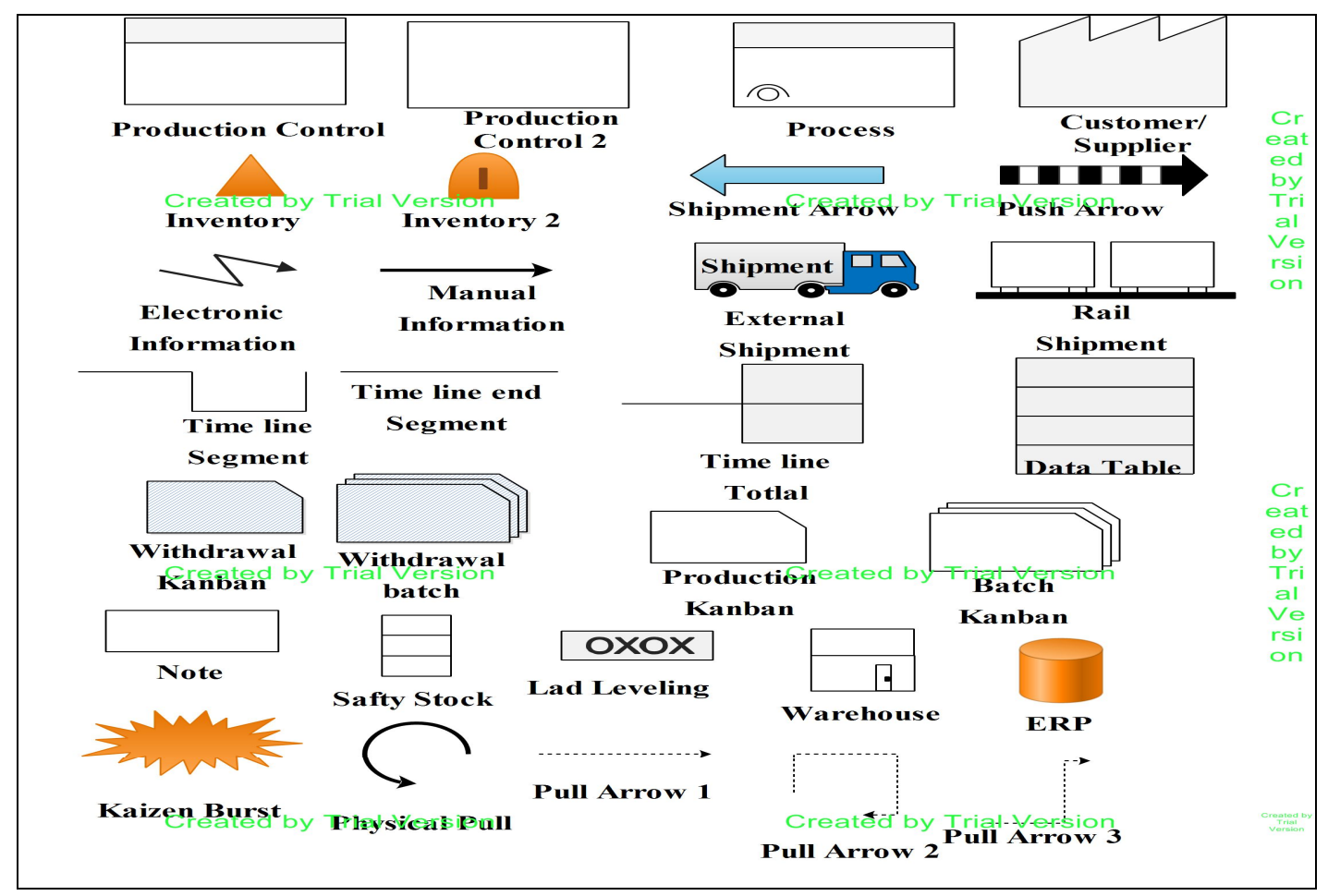

Fig.2.1Value Stream Mapping Icons [Created By Edraw Software]

\subsection{DATA BOX ELEMENTS USED IN VSM}

Metrics used to define data box element are
a.
b.
b.
c.
d.
e.
f.
g.
h.
i.
j.
$\mathrm{k}$.
1.

$\mathrm{T} / \mathrm{T}=$ Travel time

$\mathrm{P} / \mathrm{T}=$ Process time $=\mathrm{Q} / T+C / T+C / O$

$\mathrm{L} / \mathrm{T}=$ Lead time $=\mathrm{P} / \mathrm{T}+\mathrm{T} / \mathrm{T}=\mathrm{VA}$ time + NVA time

FPY $=$ First path yield $=$ Goodpieces produced $/$ Totalpiece

$\mathrm{Q} / \mathrm{T}=$ Queue time

Takt $=\frac{\text { Available work time per shif }}{\text { Customer demand quantity per shift }}$

$\mathrm{C} / \mathrm{T}=$ Cycle time

$\mathrm{C} / \mathrm{O}=$ Change over time

$\mathrm{A} / \mathrm{T}=$ Available time

Cycle efficiency $=\frac{\text { Value added time }}{\text { Lead time }}$

VA time $=$ Value added time $=\mathrm{C} / \mathrm{T}$

NVA time $=\mathrm{Q} / \mathrm{T}+\mathrm{T} / \mathrm{T}+C / O$

\subsection{PARTS OF VALUE STREAM MAP}

VSM has three main parts are shown in Fig.2.2

\section{i. Information Flows}

It is a communication method in the production system which refers to a flow of information from the customer to production control and from production control to a supplier is shown in Fig. 2.2

ii. Material Flows 
It refers to a flow of material as per the production planning and control. It shows the flow of material from one process to next process as per scheduling is shown in Fig.2.2

iii. Lead Time Ladder

It consist time line segment and time line total icon which indicate lead time and process time of production line is shown in Fig.2.2.

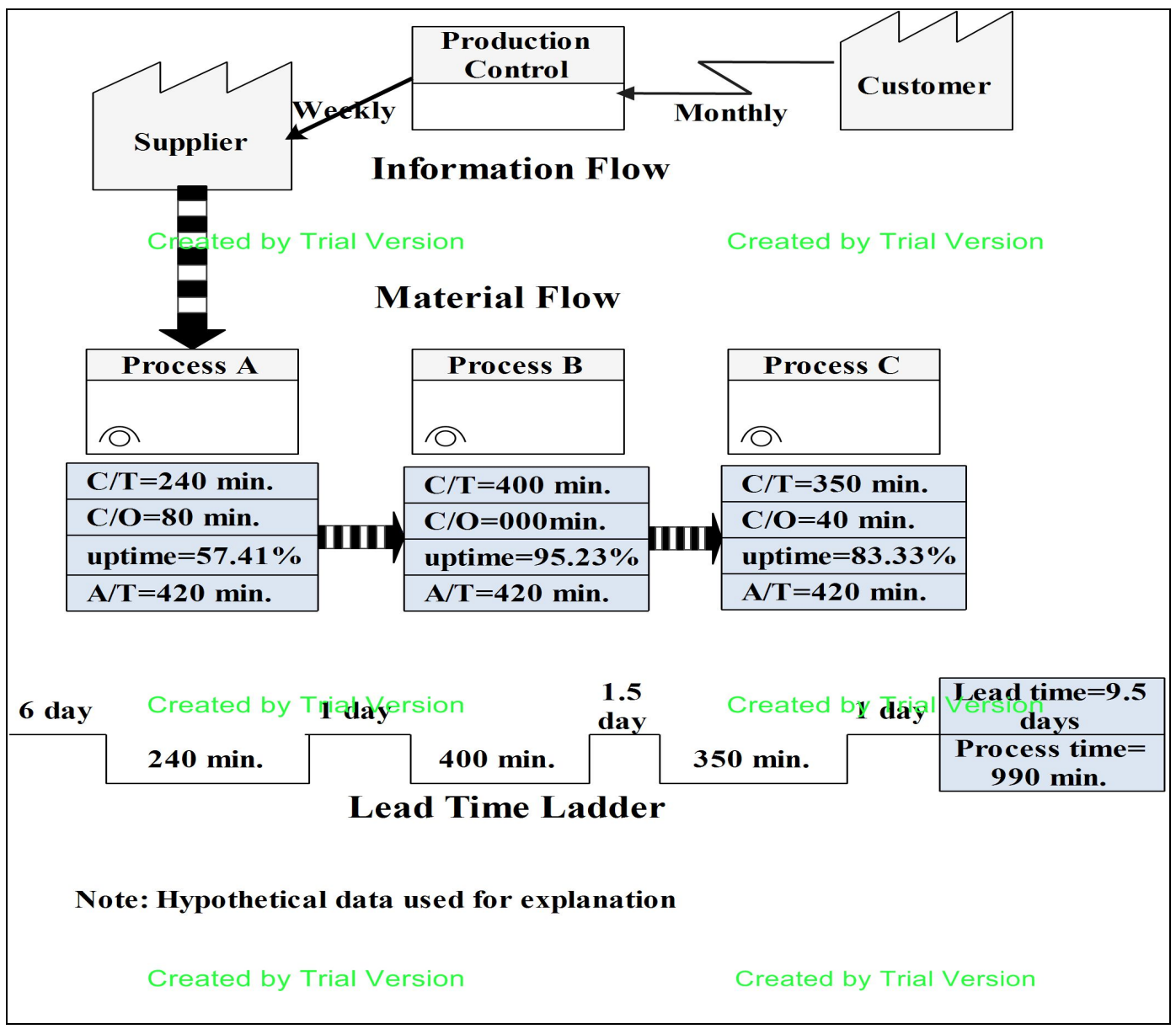

Fig.2.2 Parts of Value Stream Map [Created By Edraw Software]

\section{LITERATURE REVIEW}

Ciarniene and VienaZindiene [1] presented a model of Lean implementation process to show the main principles of Lean and disclosed the success factors in Lean implementation. Seth and Gupta [2] used the VSM as LM tool for improving productivity at supplier end by taking the case study of an auto industry. They discussed both current and future states of supplier shop floor scenarios by using value stream concepts and analyzed the VSM by takt time calculations. They achieved a gain in production output per person, reduction of work in process (WIP) inventory and finished goods inventory. Patel et al. [3] illustrated the review of VSM techniques and its benefits in machining industry. Abdulmalek et al. [5] implemented the VSM (value stream map) as Lean Manufacturing (LM) tool in the case study of a large steel mill. A Simulation model developed to contrast the "before" and "after" scenario in the case study company. Production lead-time and work-in-process (WIP) inventory reduced through VSM as LM tool in the case study company to increase productivity. Alvarez et al. [6] redesigned the assembly line of the case study 
organization by using Kanban and Milk run technique with VSM as LM tools. Achieved improvement measured in terms of the lean rate (LR) and dock-to-dock time (DtD) parameters. Eswaramoorthi et al. [7] developed an effective strategy for configuration of the assembly system using Lean concept and proposed an integrated cost model for the assembly process. Giao and Cachadinha [8] made an attempt for the use Lean construction as Lean Manufacturing tool in the construction sector. They carried out a study and identified problem and waste present in road work by implementing VSM as Lean tool. Lead time of work reduced by elimination of waste. Khalil and Mohammed [9] investigated and analyzed the wastes elimination of the manufacturing firms in Gaza Strip and analyzed its important role for reducing the production cost. The main aim of the research was to promote lean thinking through studying the seven wastes which targeted by the lean manufacturing philosophy. Rawabdeh [10] explored the relationship between seven waste of lean manufacturing (overproducing; processing; inventory; transporting; producing defects; time waiting; and motion waste) by investigating a method of waste allocation. Ramesh et al. [11] used Value Stream map (VSM) as a lean implementation tool. They carried out a practical study in a manufacturing industry for the manufacture of Machining center. Singh et al. [12] covered review and classification of literature available on VSM and presented the case study of small manufacturing Indian industry in which LM implemented through VSM (Value Stream Map) as LM tool. Lead time, processing time, work in process (WIP) inventory and manpower requirement reduced.

\section{VALUE STREAM MAPPING METHODOLOGY}

Analysis of process carried out by acquiring related information pertaining to process. The various steps followed in VSM methodology are shown in Fig.4.1

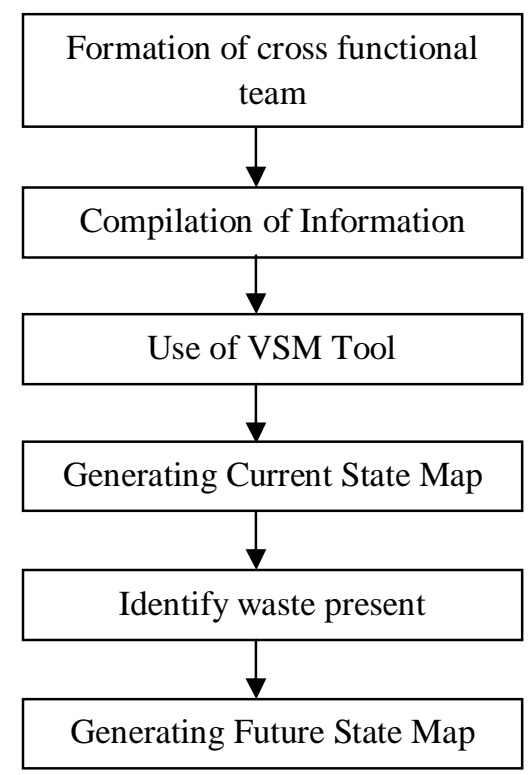

Fig.4.1 Steps in VSM Methodology

\section{A. Formation of Cross Functional Team}

A cross functional team is formed that included 4-5 persons. The function of this team is to create cultural change and collect data for study.

B. Compilation of Information -

1) Related to Demand-

Information pertaining to product family, variety of product, quantity required, Lot size, type of packing, number of delivery points are compiled.

2) Related to Information Flow- 
Information pertaining to forecasted demand, departments, methods of supply, time taken during supply and processing, ordered quantity for supply are compiled.

3) Related to Material Flow-

Information pertaining to Process layout, cycle time, change over time, available time, travel time are compiled.

C.

\section{Use of VSM Tools}

Complied information are arranged for generating map as per VSM tool which are shown in Table 4.1

Table 4.1 VSM tools

\begin{tabular}{|l|l|l|}
\hline S/N & VSM tools & Parameters \\
\hline 1 & Information flow mapping & Data related to supplier, customer and production control \\
\hline 2 & Material flow mapping & $\begin{array}{l}\text { Data related to process like C/T, C/O, T/T , A/T and } \\
\text { inventory }\end{array}$ \\
\hline 3 & Time ladder mapping & Data related to lead time, VA and NVA time \\
\hline 4 & Demand mapping & Quantity of defects less produced product \\
\hline 5 & Quality mapping & Data related to defected product and service \\
\hline 6 & Variety of product mapping & Data related to variant manufacturing process path \\
\hline
\end{tabular}

D. Generating Current State Map -

Information compiled by team is used to draw current state map. Following steps have to follow to draw a current state map.
1) Draw process layout
2) Map information flow
3) Map material flow
4) Map lead time ladder

E. Identify Waste Present

After drawing of current state map find out the waste present and also find that which tool applied to improve the process.

\section{F. Generating Future State Map}

The improvement in the existing process applying various lean tools like 5S, Kanban, Kaizen, Line balancing, etc. comes to this phase. The lean tools ultimately helps in reducing lead time, change over time, NVA time, WIP inventory and improving productivity.

\section{CONCLUSION}

It is concluded that VSM to be used as lean tool to improve process parameter. The methodology of value stream mapping implementation is expressed after referring number of papers. This paper will provide help to use VSM as lean tool to reduce waste and enhance process.

\section{ACKNOWLEDGEMENT}

I would like to acknowledge and extend my sincere gratitude to Prof. B S Pabla, NITTTR Chandigarh and Associate Prof. J P Bhamu, Gov.ECB Bikaner for their constant assistance and motivation to publish a paper.

\section{REFERENCES}


[1] Ciarniene R., and VienaZindiene M., "Lean Manufacturing: Theory and Practice", Economics and Management, Vol. 17, No.2, 2012.

[2] Seth D., and Gupta V., "Application of Value Stream Mapping for Lean Operation and Cycle Time Reduction: An Indian Case Study", Production Planning and Control, Vol. 16, pp. 44-59, 2005.

[3] Patel N., Chauhan N., and Trivedi P., "Benefits of Value Stream Mapping as A Lean Tool Implementation Manufacturing Industries: A Review", IJIRST, Vol. 1, No. 8, pp. 53-57, 2015.

[4] Tapping D., Luyster T., and Shuker, T., Value Stream Management: Eight Steps to Planning, Mapping and Sustaining Lean Improvements, New York, NY: Productivity Press, 2002.

[5] Using Lean Concepts", International Journal of Lean Thinking, Vol. 1, pp. 14-39, 2010. Abdulmalek A., and Rajgopal J., "Analyzing the Benefits of Lean Manufacturing and Value Stream Mapping Via Simulation: A Process Sector Case Study”, International Journal of Production Economics, Vol.107, pp. 223-236, 2007.

[6] Alvarez R., Calvo R., Pena M., and Domingo R., "Redesigning an Assembly line through Lean Manufacturing Tools", International Journal of Advanced Manufacturing Technology, Vol. 43, pp. 949-958, 2009.

[7] Eswaramoorthi M., Prasad P.S.S., and Mohan ram P.V.," Developing an Effective Strategy to Assembly Systems

[8] Giao J., and Cachadinha N., "Suitability and Benefits of Implementing Lean Production on Road Works", Production system design, Proceeding, IGLC, Lima Peru, pp. 579-588, 2011.

[9] Khalil A. E., and Mohammed S. A., "Seven Wastes Elimination Targeted By Lean Manufacturing Case Study Gaza Strip Manufacturing Firms", International Journal of Economics, Finance and Management Sciences, Vol. 1, No. 2, pp. 68-80, 2013.

[10] Rawabdeh I. A., "A Model for the Assessment of Waste in Job Shop Environments", International Journal of Operations and Production Management, Vol. 25, pp. 800-822, 2005.

[11] Ramesh V., Prasad K. V. S., and Srinivas T. R., "Implementation of a Lean Model for Carrying out Value Stream Mapping in a Manufacturing Industry", Journal of Industrial and Systems Engineering, Vol. 2, pp.180196, 2008.

[12] Singh B., Garg S. K., and Sharma S. K., "Value Stream Mapping: Literature Review and Implication", International Journal of Advanced Manufacturing Technology, Vol. 53, pp. 799-809, 2011. 